\title{
Preprocedural and procedural transesophageal echocardiography in patients with left atrial appendage occluder implantation
}

\section{Zorislav Šušak, \\ Ante Anić, \\ Branimir Bukša*}

Zadar General Hospital, Zadar, Croatia
RECEIVED:

March 11, 2017

ACCEPTED:

April 6, 2017
KEYWORDS: atrial appendage, occluder device, transesophageal echocardiography, atrial fibrillation, stroke.

CITATION: Cardiol Croat. 2017;12(4):131. | https://doi.org/10.15836/ccar2017.131

*ADDRESS FOR CORRESPONDENCE: Branimir Bukša, Opća bolnica Zadar, Bože Peričića 5, HR-23000 Zadar, Croatia. / Phone: +385- 23-505- 292 / E-mail: brarbuk@gmail.com

ORCID: Zorislav Šušak, http://orcid.org/0000-0003-2977-6833 • Ante Anić, http://orcid.org/0000-0002-6864-3999 Branimir Bukša, http://orcid.org/0000-0001-5206-512X

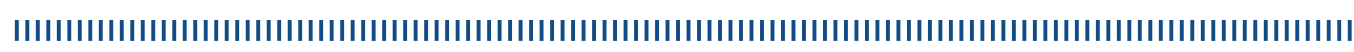

Percutaneous left atrial appendage closure for stroke prevention in patients with atrial fibrillation has distinctively advanced in recent years ${ }^{1}$. The current recommendations by the European Society of Cardiology include patients with high stroke risk and contraindications to long-term oral anticoagulation $^{2}$. Preprocedural transesophageal echocardiography remains the reference technique to exclude the presence of left atrial appendage thrombi prior to left atrial appendage closure and to assess left atrial appendage anatomy and accurate measurements regarding challenging anatomies and device sizing ${ }^{3}$. Procedural transesophageal guidance is generally recommended with any current CE mark device in addition to fluoroscopy. Transseptal puncture is well positioned with transesophageal bicaval and short axis views. Device sizing depends on the widest landing zone on fluoroscopy or transesophageal echocardiography which is by standard recommendation upsized by $2-5 \mathrm{~mm}$. Device is adequately positioned at landing zone and deployment is controlled by transesophageal echocardiography and fluoroscopy. Prior to device release, evaluation of proper deployment is done by transesophageal echocardiography. Finally, after deployment additional assessment of possible residual flow is performed. Procedural transesophageal guidance is widely available imaging method which is contributing to procedural success and safety. We would like with our patients series to depict key procedural steps.

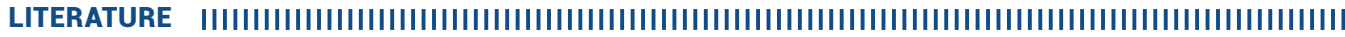

1. Freixa X, Chan JL, Tzikas A, Garceau P, Basmadjian A, Ibrahim R. The Amplatzer ${ }^{\mathrm{TM}}$ Cardiac Plug 2 for left atrial appendage occlusion: novel features and first-in-man experience. EuroIntervention. 2013 Jan 22;8(9):1094-8. https://doi.org/10.4244/EIJV8I9A167

2. Camm AJ, Lip GY, De Caterina R, Savelieva I, Atar D, Hohnloser SH, et al; ESC Committee for Practice Guidelines (CPG). 2012 focused update of the ESC Guidelines for the management of atrial fibrillation: an update of the 2010 ESC Guidelines for the management of atrial fibrillation. Developed with the special contribution of the European Heart Rhythm Association. Eur Heart J. 2012 Nov:33(21):2719-47. https://doi.org/10.1093/eurheartj/ehs253

3. Saw J, Lempereur M. Percutaneous left atrial appendage closure: procedural techniques and outcomes. JACC Cardiovasc Interv. 2014 Nov;7(11):1205-20. https://doi.org/10.1016/j.jcin.2014.05.026 